admission. This proportion could already be greater in some parts of the country and may increase if referrals of cases of self-poisoning increase faster than the facilities for their assessment and management. The provision of social work and psychiatric expertise in casualty departments may be one means of preventing unnecessary medical admissions without risk to the patients.

Dr Blake's and Dr Bramble's figures do not demonstrate, however, that any advantage would attach to medical teams taking over assessment from psychiatrists except that, by implication, assessments would be completed sooner by staff working on the ward full time. What the figures actually suggest is that if assessment of overdoses were left to house doctors there would be an increase in admissions to psychiatric units (by $19 \%$ ), outpatients (by $5 \%$ ), and referrals to social services (by $14 \%$ ). So for house doctors to assess overdoses would provide no economy for the psychiatric or social services. The study does not tell us what the consequences would have been for the six patients who the psychiatrists would have admitted but to whom the house doctors would have offered outpatient appointments.

E J SALTER

King's Mill Hospital,

Sutton-in-Ashfield, Notts NG17 4JL

\section{Vitamin D deficiency in Asian immigrants}

SIR,-We agree with your leading article on rickets in the Asian community (30 June, $\mathrm{p}$ 1744) that the diet of Asians should be supplemented with vitamin $\mathrm{D}$, and that attempts to change dietary customs for health reasons are doomed to failure. Nevertheless, we feel that the special need to ensure adequate vitamin $\mathrm{D}$ intake in certain high-risk groups has not been properly emphasised.

The risk of vitamin D deficiency is probably greatest during pregnancy and this risk is not offset by sunlight in the UK. There is certainly more sunlight in London than in Glasgow; nevertheless, in our recently completed double blind trial of vitamin D supplements in pregnancy, $22 \%$ of a placebo group of 60 predominantly middle-class Asian women had plasma $25-\mathrm{OH}$ vitamin $\mathrm{D}$ levels of less than $5 \mathrm{nmol} / \mathrm{l}$ at 28 weeks of pregnancy. At parturition this proportion had increased to $40 \%$, and $45 \%$ of their infants had equally low levels in their cord blood. Such low levels are often associated with osteomalacia and rickets. Five of the infants of the mothers in the placebo group had symptomatic hypocalcaemia in the neonatal period, while none of the 59 infants in the treatment group were affected. After making allowance for the

Comparison of heat-labile alkaline phosphatase concentrations in maternal and umbilical cord plasma of patients receiving vitamin D supplements and those receiving placebo

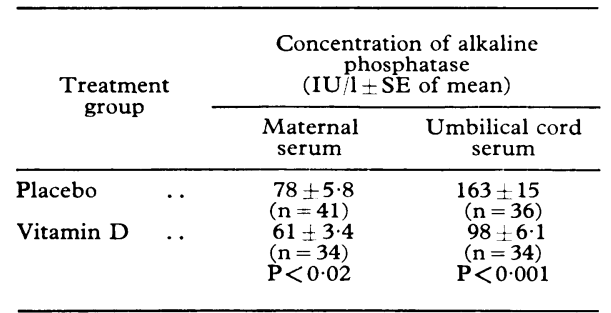

placental isoenzyme, plasma alkaline phosphatase was elevated in the placebo mothers and their infants compared with the treated group (table). Since none of the mothers had raised plasma levels of liver enzymes and since it is known that the bone isoenzyme accounts for more than $80 \%$ of the cord blood activity, these alkaline phosphatase results probably imply subclinical bone disease.

These findings are in preparation for publication but in the meanwhile we would urge all, and in particular obstetricians, who care for pregnant Asian women to ensure that their patients receive adequate vitamin $\mathrm{D}$ supplements.

O G BROOKE

I R F BROWN

H J W Cleeve

St George's Hospital

London SW 17 ORE

SIR,-Two statements in your leading article (30 June, p 1744) might be misleading. The opening sentence states that "rickets virtually disappeared from Britain in 1945 after milk was fortified with vitamin D." It should be made clear that the only milks in Britain fortified with this vitamin are those used for the artificial feeding of infants. At no time has "doorstep" milk been fortified. The second statement which requires clarification is that "rickets and osteomalacia are now found mostly in Asian immigrants to Britain." It is, of course, true that a number of cases of rachitic deformity are found in Asian immigrants, but the problem of vitamin $D$ deficiency is also seen in children of Asian ethnic origin born and reared in the UK. This is of equal or greater concern to health authorities than the occurrence of rickets in those entering the country from Asia or Africa.

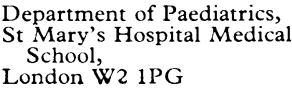

\section{Age and death in breast cancer}

SIR,-Your leading article (27 January, p 211), prompted a preliminary review of some material being collected at Saint Elizabeths Hospital on breast cancer in mental patients. The total number of cases operated on since 1959 is 135, of which 43 records have been reviewed. The total involved population is taken as the estimated female population plus admissions since 1959, a total of 21631 females. The estimated prevalence in this group would be $730 .{ }^{1}$ The true figure is undoubtedly higher since many patients were hospitalised only briefly and lost to follow-up. Patients fell into three diagnostic categories: organic brain syndrome with psychosis (DSM II 290.X294.X), organic brain syndrome without psychosis (DSM II 309.X), and schizophrenia (DSM II 295.X).

Comparison of age of onset of breast cancer and survival suggests that survival decreases with age of onset of breast cancer and calculation of the correlation coefficient confirms this: $\mathrm{r}=-0.4456, t=3.1865, \mathrm{P}<0.005$. This higher death rate, however, is not entirely due to breast cancer but to age per se. Fourteen patients died of breast cancer, 18 from other causes and were clinically free of disease. Age of onset for these groups was $77 \cdot 1 \pm 11$ and $74 \cdot 9 \pm 14 \cdot 6$ respectively, which is not a significant difference and suggests that age of onset does not affect survival either positively or negatively. Various treatments were assigned numerical values which were totalled and averaged for each group. Correlation of survival against treatment gives a disappointing $\mathrm{r}=0.038$. This is misleading because patients with anaplastic or advanced disease receive more chemotherapy and radiation. Older patients, however, tend to be treated more conservatively: for age of onset of breast cancer against treatment: $\mathrm{r}=-0.2774, t=$ $1 \cdot 8494, \mathrm{P}<0 \cdot 1$; not significant, but suggestive. In recent months, considerable interest has been expressed in the possible effect of phenothiazines on the development of breast cancer. ${ }^{2}$ Patients who receive phenothiazines prior to development of breast cancer live longer than those who never received these drugs; but the significance of this is clouded by the marked differences in age. Twenty-five patients who received phenothiazines before developing breast cancer may be compared with 18 who did not receive these drugs. Survival was $3 \cdot 22 \pm 3 \cdot 1$ years for the non-drug group and $4.88 \pm 4 \cdot 3$ years for the phenothiazine group, giving a $t$ of 1.3684 with $P<0.02$. This strongly suggests that, at the worst, phenothiazines do not exert any adverse effects on survival.

Reserpine has also been implicated as a carcinogen. ${ }^{3}$ Comparison of dosage against survival gives an $r$ of $0 \cdot 1445$, which does not support any effect of reserpine on breast cancer: however, there are only nine patients in this group.

The prevalence of breast cancer in schizophrenics appears to be much lower than expected, a phenomenon which has been claimed for cancer in general. ${ }^{4}$

JoHN M GOWDY JAMES D SOLOMON

National Institute of Mental Health,

Washington DC 20032

${ }^{1}$ Seidman, $\mathrm{H}, \mathrm{Ca}-\mathrm{A}$ Cancer fournal for Clinicians,

1978, 27, 66. Smithline, F, and Meltzer, H Y, Archives of General sychiatry, 1978, 3al 1291.
Robinson, B, Medical fournal of Australia, 1957, 2, 239.

- Roppel, R M, Science, 1977, 201, 398.

SIR,-I am surprised that no one has objected to the leading article "Age and death in breast cancer" (27 January, p 211). Anxiety has been aroused in women who had had mastectomy for breast cancer some years before and who, though medically or scientifically untrained, had easy access to the journal. Their distress was caused by their subjective interpretation of an unscientific phrase used in that article-namely, ". . . most women who develop carcinoma of the breast are likely to die of their cancer." Their interpretation was "However long I survive, I am almost certain to suffer death from cancer."

Condemnation of the use of this phrase involves its repetition, with the concomitant risk of causing more distress. (Perhaps this explains the absence of any subsequent reproof from these columns.) Only if its origin is discredited can the unfortunate consequences of its use be mitigated, and the phrase itself consigned to its rightful place in that journalistic limbo between scientific sophistry and aphoristic brevity. The offending phrase is a misquotation from a paper by Mueller et $a l,{ }^{1}$ the paper whose findings and conclusions formed the basis of the leading article, and a paper therefore which your 
readers might assume can be "taken as read." Hence I was astonished to find that only two of its seven conclusions (and these two were statements of the obvious) could withstand rigorous scrutiny.

I would thus challenge the assertion by Mueller et al that breast cancer is most rapidly lethal in the elderly, and suggest that the authors have erred in completely ignoring the possibility that the disease is diagnosed relatively late in older women. The recent paper by Dr W H Redding and his colleagues on age and prognosis in breast cancer (2 June, p 1465) comes to the same conclusion.

\section{David Belasco}

\section{Swaffham, Norfolk PE37 8DD}

1 Mueller, C B, Ames, F, and Anderson, G D, Surgery, $1978,83,123$

** It is an uncomfortable though hardly an unscientific fact that the majority of women who present with carcinoma of the breast will die of their disease. For a start, something like $30-40 \%$ of all women who present with breast cancer have either locally advanced or widely disseminated disease on presentation. ${ }^{1}$ This group as a whole have little chance of living five years after diagnosis. ${ }^{1}$ The remainder presenting with "operable or potentially curable" breast cancer can be expected to demonstrate an approximate $50 \%$ 10-year survival, irrespective of primary modalities of therapy." Ten years' survival, however, does not in itself guarantee cure, and two series with long-term follow-up have clearly demonstrated that the excess risk of dying applies up to 20 years or more after primary therapy, providing an estimated $30 \%$ cure rate. ${ }^{34}$ The data have nothing to do with Mueller's article and should be widely known to all clinicians involved in the treatment of breast cancer. If uncomfortable facts cannot be published in a medical journal, then we would indeed be burying our heads in the sand.

It is true that in Mueller's article, and also in the short paper by Dr Redding and his colleagues, there was a small disproportionate increase in the incidence of stage III and unstaged breast cancers among the elderly. However, Mueller and his colleagues took the trouble to exclude the unstaged cases from the analysis and to correct according to stage at diagnosis in making their comparisons between the age groups. Thus, to quote from their conclusion, "Age as well as stage at diagnosis are significant determinants of the length of survival and cause of death." But "late" breast cancer may in part reflect its aggressive nature and not simply the delay in presentation on the patients' part. ${ }^{5}-\mathrm{ED}, B M \mathcal{F}$.

${ }^{1}$ Cutler, S J, Seminars in Oncology, 1974, 1, 91.

2 Fisher, B, Cancer, 1973, 31, 1271

3 Adair, F, et al, Cancer, 1974, 33, 1145

Arinkley, D, and Haybittle, J L, Lancet, 1975, 2, 95

5 Devitt, J E, in Risk Factors in Breast Cancer, ed B A Stoll, p 110. London, Heinemann Medical, 1976.

\section{Costs of unnecessary tests}

SIR,-Dr Gerald Sandler's timely and important paper (7 July, p 21) on the cost of unnecessary tests omitted one relevant fact. The unnecessary investigations performed by the doctor in outpatients have already probably been unnecessarily performed by the GP, and the results given in the referral letter. Discussions with colleagues from around the country suggest that it is very rare for such prereferral tests not to be repeated in the clinic. The potential saving from dropping at least one tier of this over-investigation could be huge.

\section{Haslam}

Huntingdon, Cambs

\section{Seat-belt legislation}

SIR,-Dr Gordon Avery (9 June, p 1561) assumes that infringement of a law enforcing the use of seat belts would be easy to detect. During a recent holiday in Spain, however, where the wearing of seat belts outside urban areas is compulsory, I discovered that those who object to wearing seat belts have a simple method of getting round the law. They pass the seat belt across their bodies but do not fasten the buckle. This makes detection practically impossible; though in the event of an accident the pattern of injury might well reveal the true situation.

This way round the law, far from making things more difficult for the police, removes two of the main objections to the introduction of legislation. In the first place, it means that any motorist with a conscientious objection to the use of a seat belt could continue to exercise his conscience without fear of detection. Also, since detection in these circumstances is practically impossible, the police would have no major problem of enforcement.

The most important deterrent to disobeying the law would come, however, not from the police, but from the insurance companies. If the wearing of seat belts were made compulsory then, in the event of an accident resulting in injury that would have been prevented by the wearing of a seat belt, the insurance companies could impose much stiffer penalties with the backing of the law. I am sure that widespread publicity regarding reduction of the damages to those who do not wear seat belts would do far more to encourage conformity to the law than any police measures.

We should therefore cease concerning ourselves with the imaginary problem of the $10 \%$ who will refuse to wear seat belts and concentrate on the known benefits to the $90 \%$ who will obey the law.

A W FOWLER

Bridgend General Hospital, Mid Glamorgan

\section{Diazepam and traffic accidents}

SIR,-In the epidemiological survey by Dr D C G Skegg and others (7 April, p 917) it was clearly shown that drivers who receive minor tranquillisers are significantly over-represented among accident victims. The authors also point out that studies of this type fail to distinguish between the effects of the drug and of the condition being treated.

People are prescribed tranquillisers because they are anxious, aggressive, or depressed, and it is recognised that these patients are more likely to be involved in accidents. ${ }^{1}$ Notwithstanding numerous claims, the detrimental effect of diazepam on driving ability has never been established. There is considerable evidence that critical flicker fusion frequency is significantly reduced by small doses of diazepam. No case has been made, however, that reduced critical flicker fusion frequency is in any way deleterious to driving ability. A statistically significant increase and reduction in reaction time (both have been reported) does not necessarily harm driving performance. Some psychomotor tests have shown that benzodiazepines at times improve and at other times impair performance: no relationship between these skills and driving ability has been established. The presence of diazepam and its metabolites in the blood of drivers involved in car accidents varies from under $2 \%$ in a recent New Zealand study ${ }^{2}$ to nearly $20 \%$ in an older Norwegian survey. ${ }^{3}$

As a general rule, it is preferable that anxious, aggressive, and depressed patients do not drive: with diazepam medication ${ }^{*}$ driving safety could deteriorate, remain unchanged, or improve.

A LANDAUER

University of Western Australia,
Nedlands, Western Australia 6009

${ }^{1}$ Milner, G, Drugs and Driving. Basle, Karger, 1972. Missen, A W, et al, New Zealand Medical fournal, $1978,87,275$

Bø, O, et al, in Alcohol, Drugs and Traffic Safety, ed $S$ Israelstam and S Lambert. Toronto, Addiction Research Foundation, 1975.

\section{Whooping cough after stopping pertussis} immunisation

SIR,-For too long the whooping cough debate has been fuelled by data whose interpretation leaves too much to speculation. Dr Robert $\mathrm{K}$ Ditchburn's (16 June, p 1601) study is no exception. The attack rate in children aged $3 \frac{1}{2}$ to 15 years is $45 \%$. It would be valuable to see the age incidence of these cases and it would shed light either on the efficacy of the vaccine with age or on an unusual pattern of attack in older children.

The Keyworth study ${ }^{1}$ showed reducing protection of the vaccine up to 5 years, but this was evident only because there was an adequate control group. Surely it is unreasonable to compare $3 \frac{1}{2}$ to 15 year olds with under $3 \frac{1}{2}$ year olds.

The Keyworth study showed $84.4 \%$ protection in 1 to 4 year olds. If I recalculate my data using Dr Ditchburn's system and compare unimmunised children under $3 \frac{1}{2}$ with immunised children aged $3 \frac{1}{2}$ to 7 years, the apparent protection falls to $50 \%$ - a very important difference.

Douglas Jenkinson Keyworth Health Centre,
Keyworth, Notts NG12 5JU

${ }^{1}$ Jenkinson, D, British Medical fournal, 1978, 2, 577.

** We sent a copy of this letter to the author, whose reply is printed below.-ED, $B M \mathcal{H}$.

SIR,-I thank Dr Douglas Jenkinson for his comments on my paper. In the outbreak I describe, whooping cough occurred in six of seven immunised children aged $3 \frac{1}{2}$ to 5 years; in 18 of 42 aged 6 to 10 years; and in 22 of 44 children aged 11 to 15 years. Thus any reduction of vaccine efficiency with age, if it occurred, must have been before the age of $3 \frac{1}{2}$ years.

I do not accept that the pattern of attack in older children is necessarily unusual, though in remote Shetland it could well be so. Until there are more studies in which the unaffected children are positively identified, the "usual" attack rate in older children will not be known.

I accept the limitations of comparing children in different age groups. Of course, if it is true that young children are more susceptible to whooping cough, my study comparing young immunised children with 